\title{
THE INDICATIONS OF NATURE IN MODERN OMANI POETRY: A DESCRIPTIVE STUDY

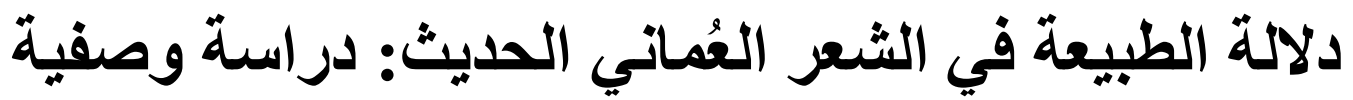

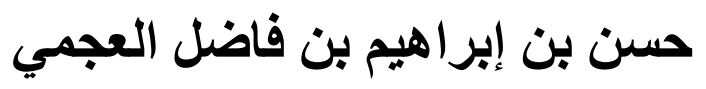

\section{Hassan Ibrahim Fadhil Ajmi ${ }^{1 *}$, Majdi Bin Haji Ibrahim² and Yasir Bin Ismail ${ }^{3}$}

${ }^{1}$ Ph.D. Candidate in Arabic Linguistic Studies Kuliyyah of Islamic Revealed Knowledge and Human Sciences, International Islamic University Malaysia (IIUM), ha44an@hotmail.com

${ }^{2}$ Prof. Dr. Kuliyyah of Islamic Revealed Knowledge and Human Sciences, International Islamic University Malaysia (IIUM), majdi@iium.edu.my

${ }^{3}$ Dr. Senior Lecturer, Kuliyyah of Islamic Revealed Knowledge And Human Sciences, International Islamic University Malaysia (IIUM), dryasir@iium.edu.my

${ }^{*}$ Corresponding Author

\begin{abstract}
This study discusses the significance of nature in modern Omani poetry when nature formed the emotion and spirit of many poets. The problem emerged in the large number of books and researches that dealt with the analysis and study of Omani poetry, but the researcher did not find anything that would help him in searching for natural words and their connotations in Omani poetry, and for this he decided to search for this phenomenon and its impact. The aim of the study is: To investigate the phenomena of nature in Omani poetry, and its effect on poetic emotion and artistic depiction on the poem's systems among Omanis. Through the descriptive and analytical approach, in collecting data from sources and documents and discussing them scientifically, the study reached the following results: The intimate link between Omani poetry and Arabic poetry does not break; there is no phenomenon in Arabic poetry except it is present in Omani poetry, including the phenomenon of nature. Omani poetry has accurately portrayed nature. This made the poet's sincerity and passion so strong that you can hardly see it in all Omani poems. Nature had an impact on many Omani poets, which made them talk about it, and that is evidence of the purity and qualities of the Omani environment, as well as the ancient Arab environment.
\end{abstract}

Keywords: connotation, nature, Omani poetry.<smiles>[Mg][Mg]</smiles>

ناقشت هذه الدر اسة دلالة الطبيعة في الثعر العُماني الحديث، حين شكلت الطبيعة العاطفة و الروح لاى كثير من الثعراء، فهي الباعث للثاعر العربي فتحث عنها في وصفه لليل و البيداء و المناظر الطبيعية التي تعايث معهاً برزته المشكلة في كثرة الكتب والأبحاث التي تناولت بـات بالتحليل

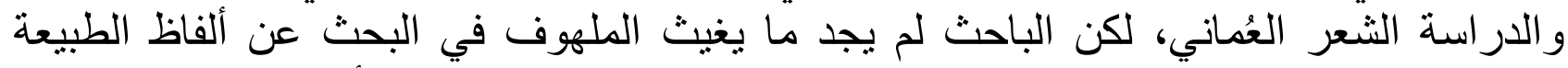

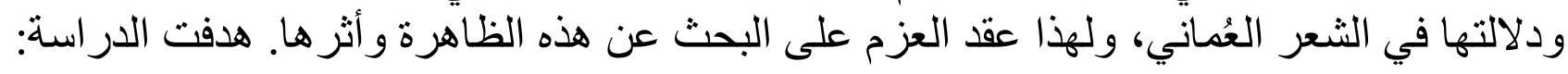


تقصي ظو اهر الطبيعة في الثعر العُماني، وأثر ذلك في العاطفة الثعرية والتصوير الفني في نظم

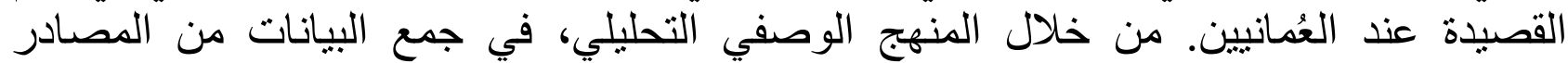

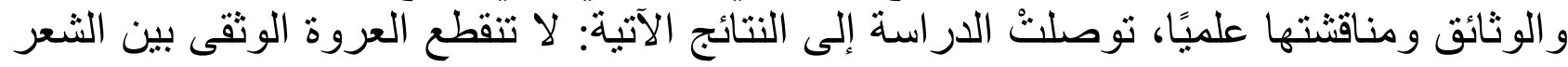

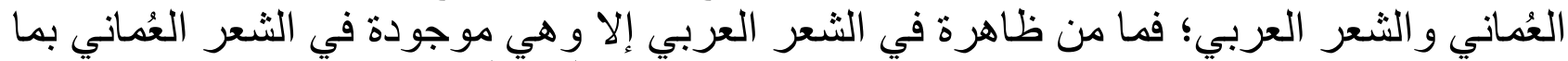

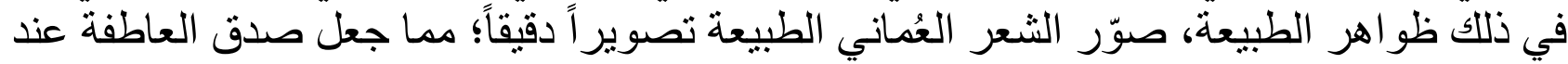

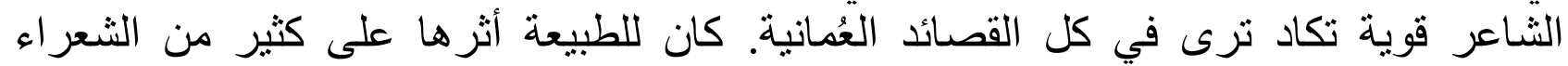

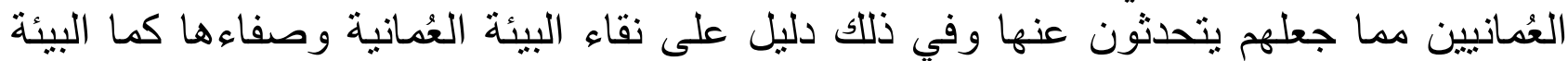
العربية القديمة. الكلمات المفتاحية: الدلالة، الطبيعة، الثعر العُماني.

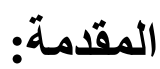

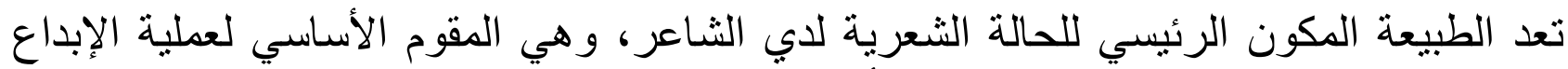

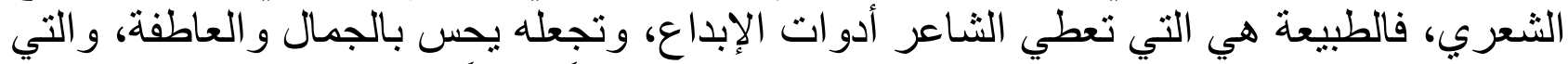

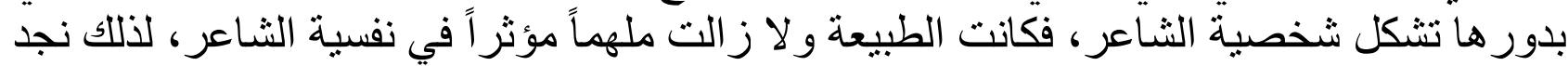

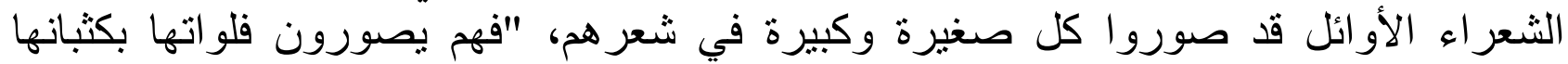

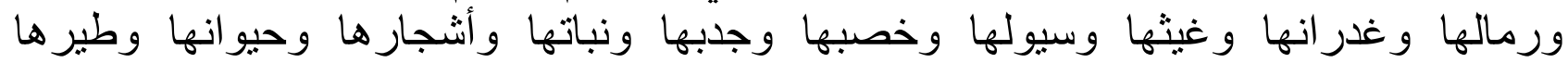

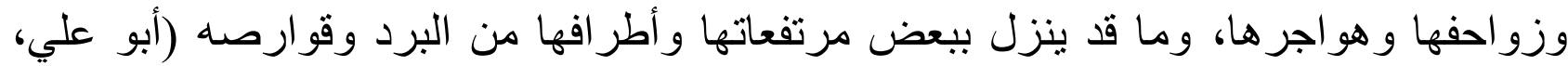
. $52: 2018$

و الثناعر في كل مكان و زمان يعبر عن همومه و مشاكل مجتمعه، متخذا أساليب عدة لتوصيل

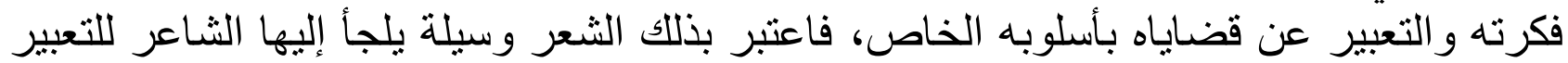

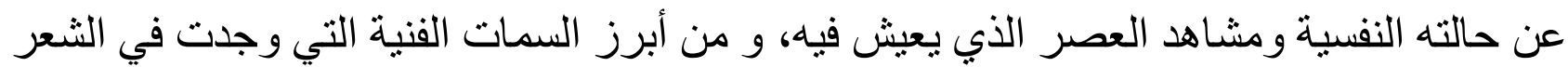

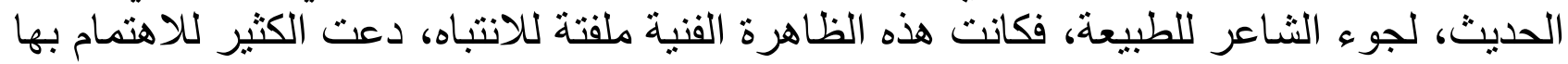

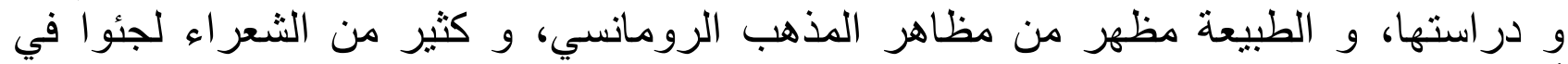

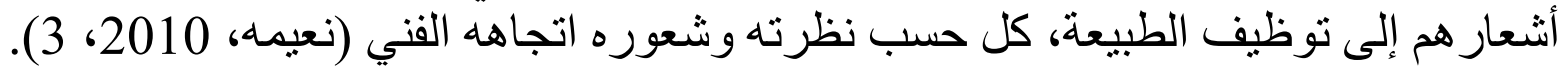

\section{تعريف الطبيعة:}

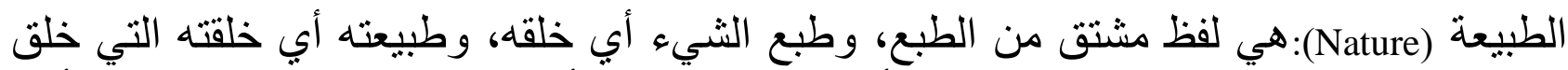

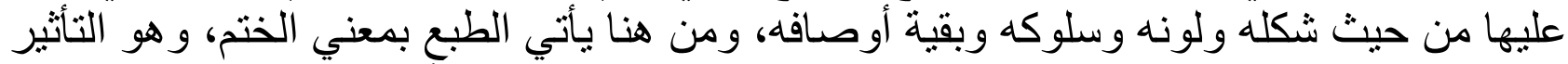

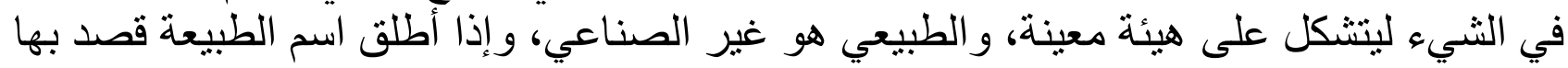

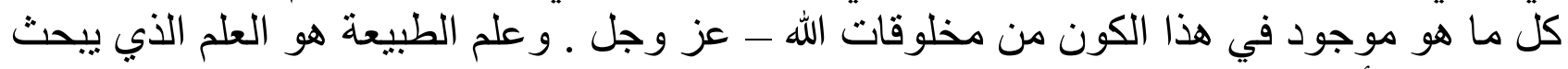
في طبائع الأشياء، وما فو في هذا لتصت به (كنعان، 2002: 52).

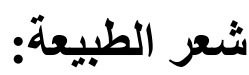

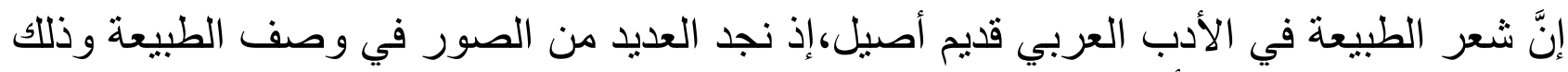

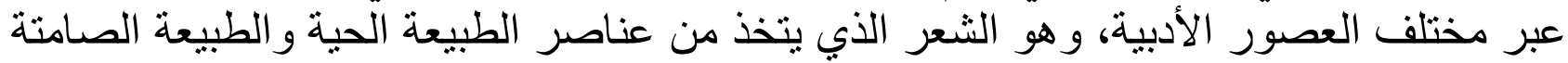

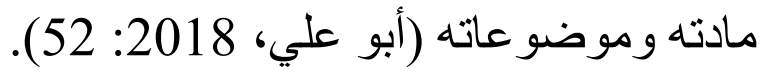
كانت الطبيعة صامتها ومتحركها من قديم الزمن موضع اهتمام الإنسان، يلجأ إليها للتعبير و التمثيل. 
فقد امتزج بها حيث استطاع أن يشاهدها بسهولة. أما وصف الطبيعة في الأدب العربي فليس

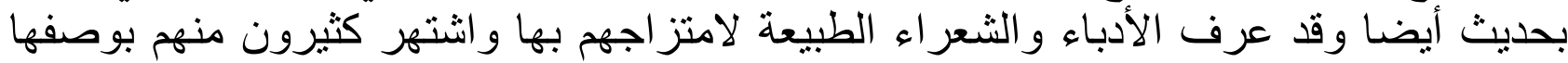

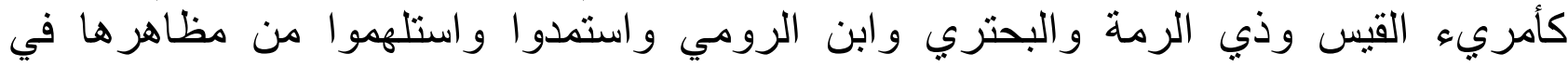

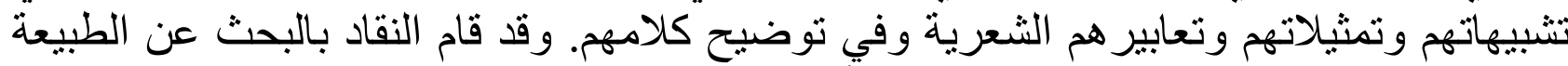

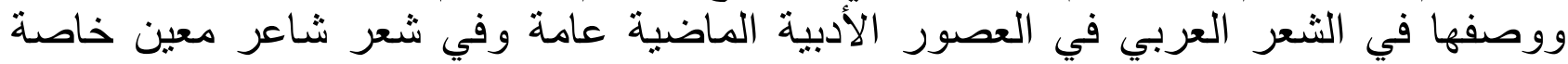

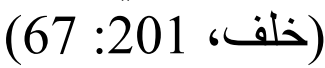

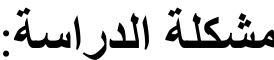

وجد الباحث كثرة الكتب و البحوث التي تتاولت بالتحليل والدراسة الثُعر العُماني، لكنه لم أجد ما العا

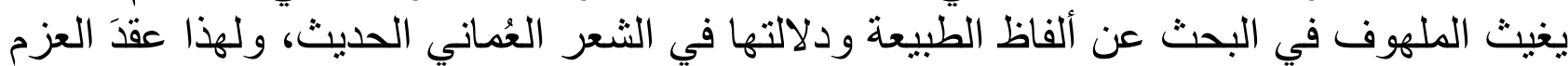

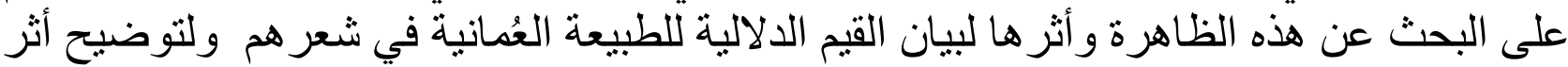
البيئة في الثُعر اء العُمانبين.

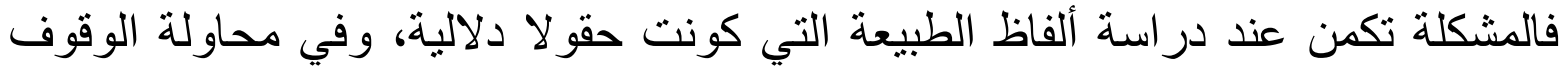

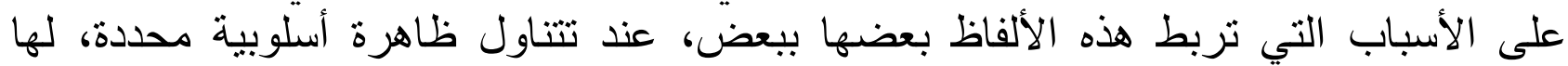

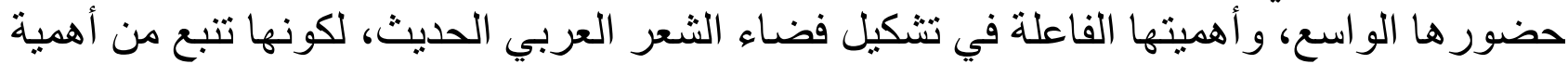

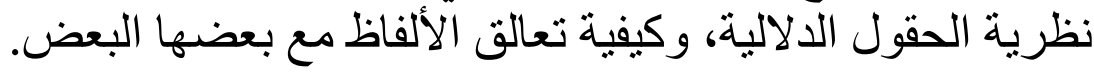

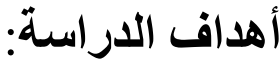
أ. مناقتنة ظواهر الطبيعية في الثعر العُماني الحديث.

ب. بيان أثر تلك الظواهر في العاطفة الشعرية والتصوير الفني في نظم القصيدة عند العُمانيين.

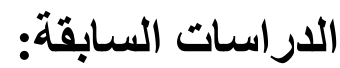

دراسة الزبير، علي عبده أحمد صالح (2010): تجليات الطبيعة في شعر الهمداني. ذكر فيه إنَّ وانَ

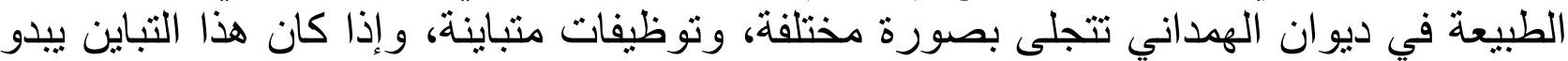

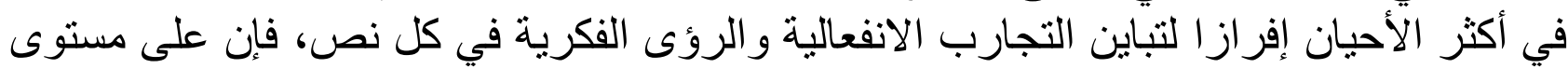

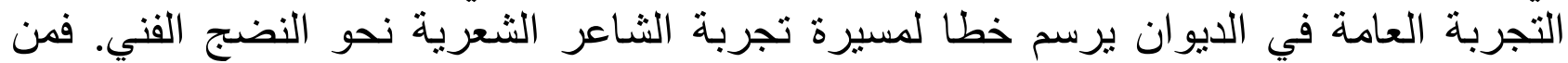

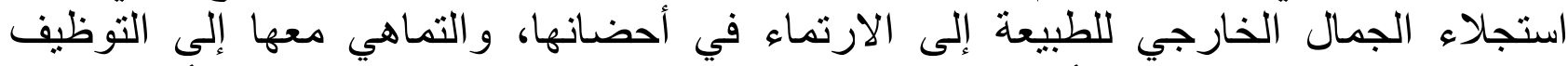

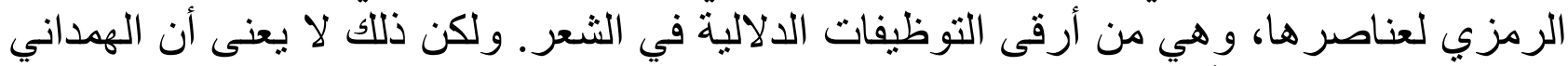

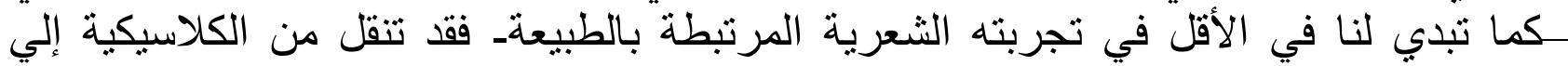

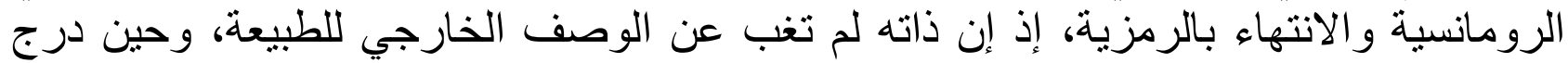

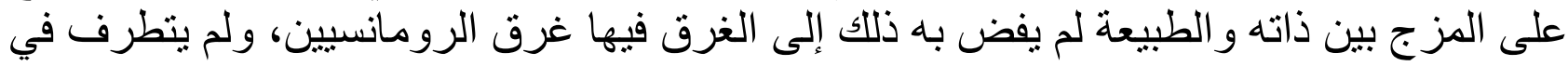

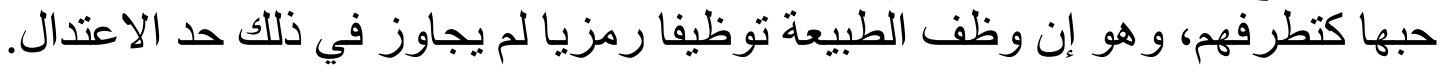

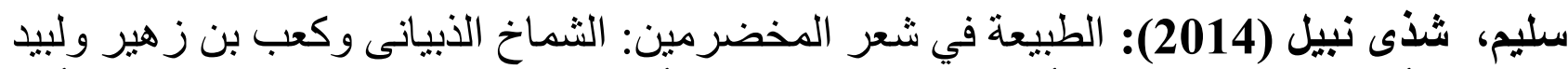

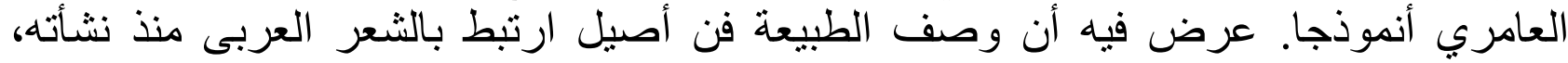

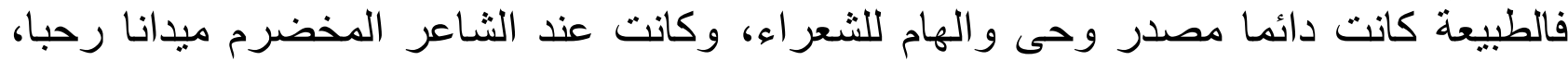

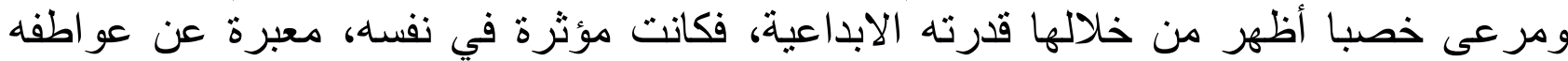

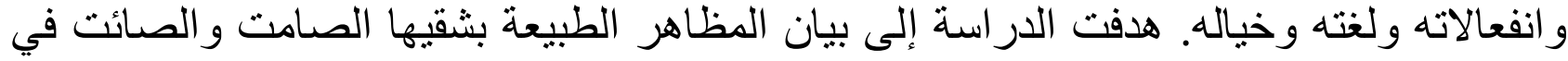




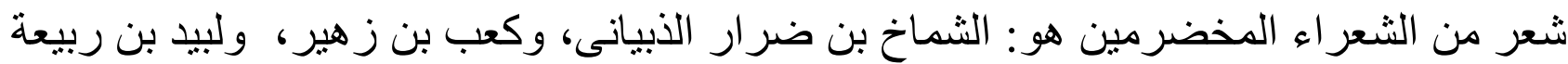

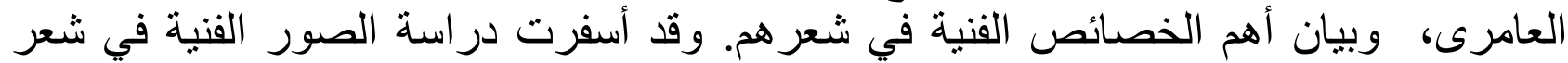

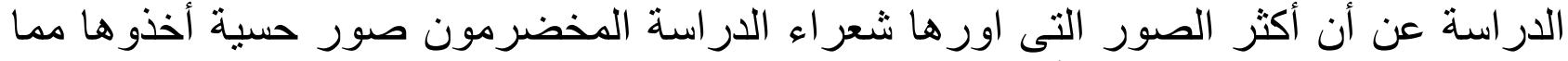

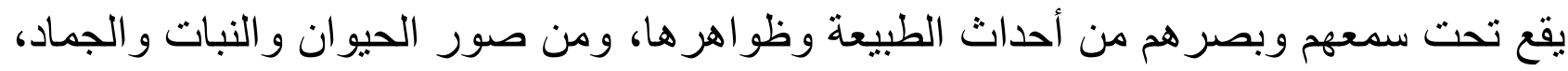
ووظفوا المتنوع من هذه الصور الحسية في خدمة معانيهم التى كان لهان التها عميق الاثر في نفوس

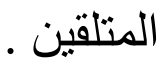

دراسة أبو علي، خالد نبيل (2018): ألفاظ الطبيعة في جمهرة أثنعار العرب: دراسة أسلوبية.

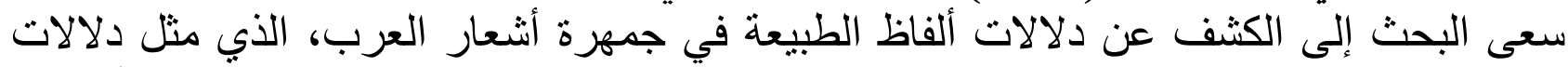

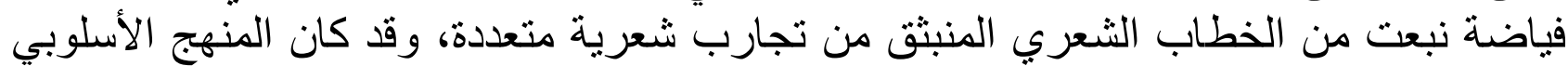

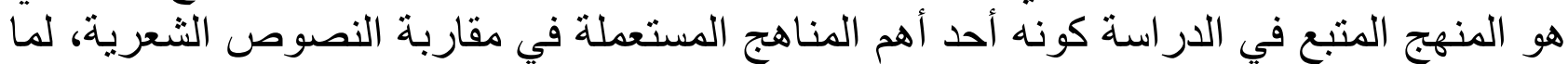

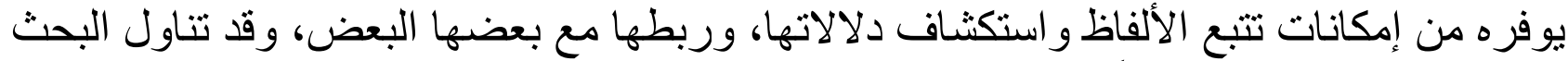

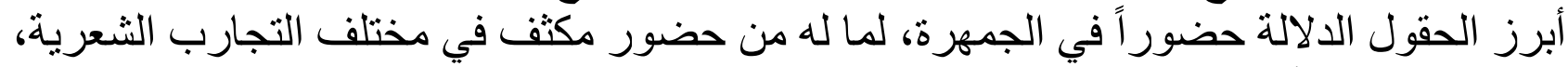

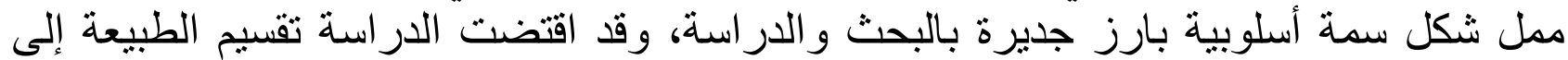

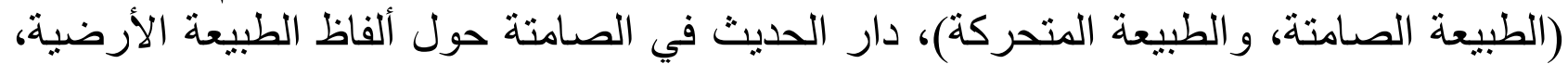
و ألفاظ الطبيعة السماوية، و ألفاظ النبات، أما ألفاظ الطبيعة المتحركة فدار الحديث فيها حول الطية الناقة

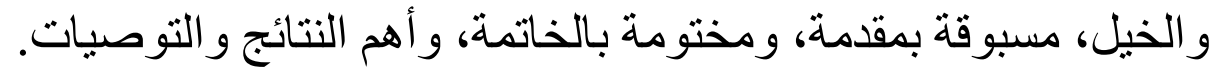

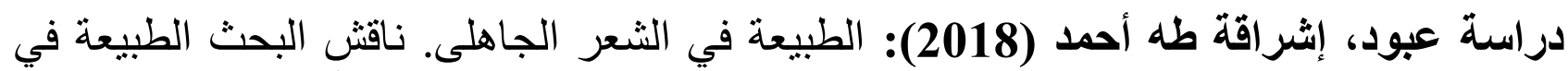

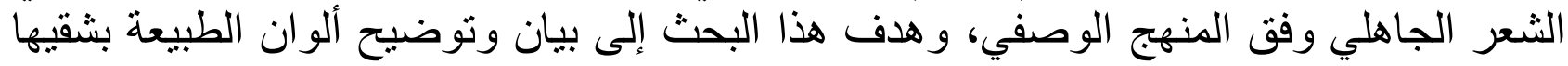

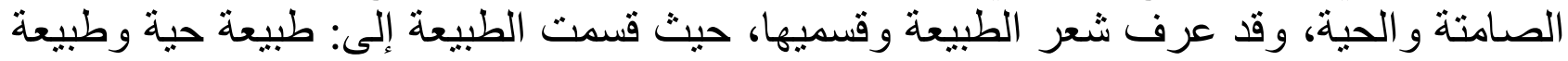

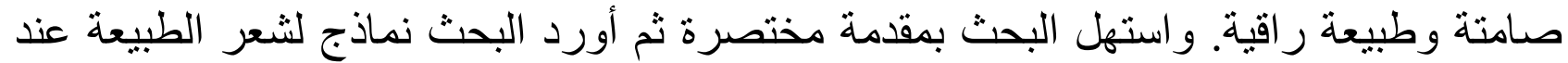

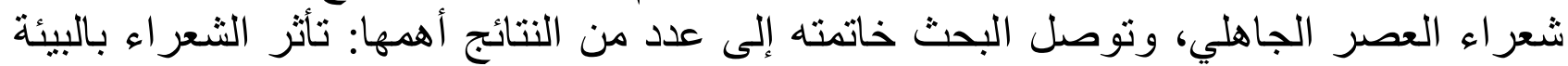
و التي تمثل الطبيعة جزء اء مهما منها، ظهر هذا ونا التأثر في شعر هم.

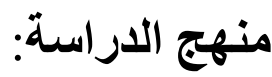

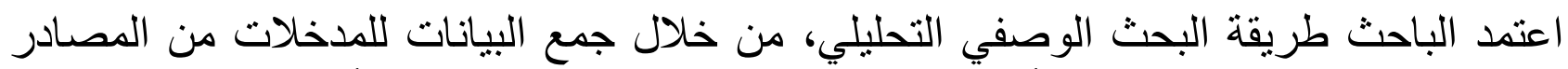

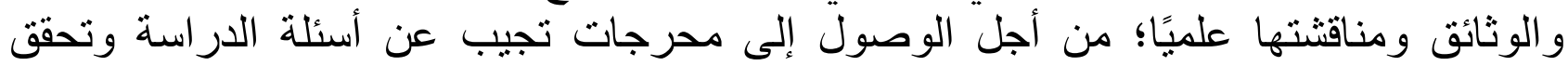
أهدافها.

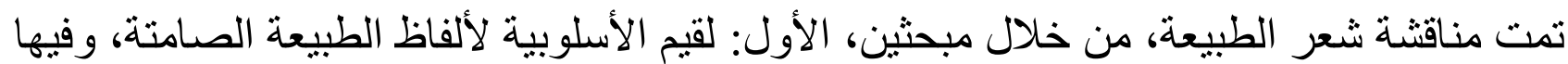

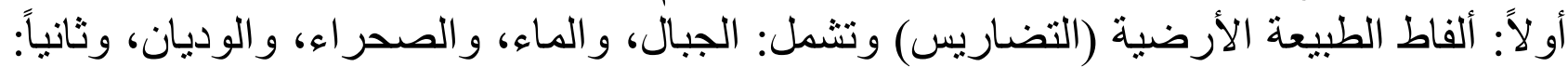

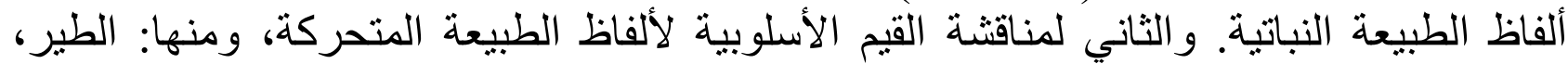

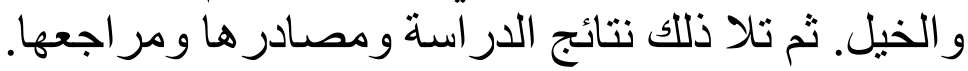
المبحث الأول: القيم الأسلوبية لألفاظ الطبيعة الصامتة دلة دانة

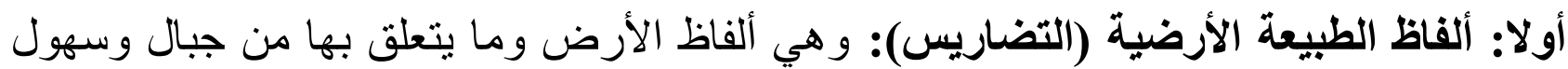
ووديان و أنهار . 


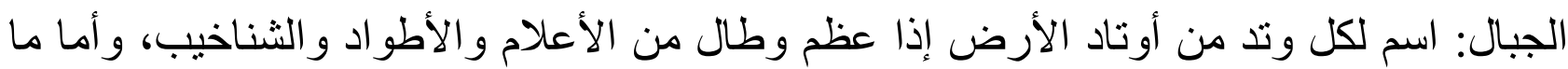

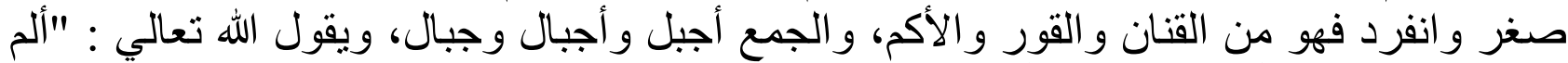

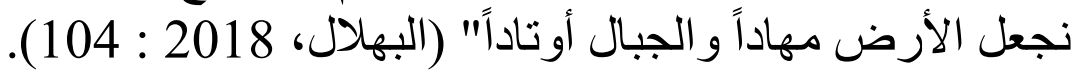

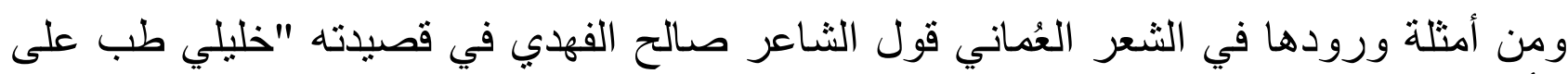

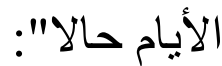

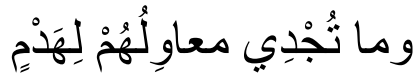

$$
\begin{aligned}
& \text { وإِنْ هَدُّو ا بها يو ماً جبالَا! }
\end{aligned}
$$

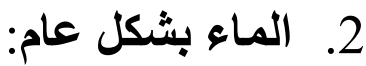

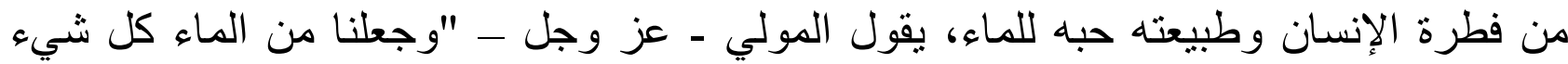

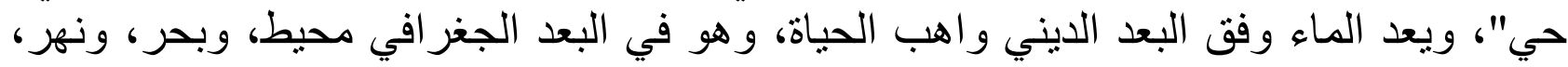

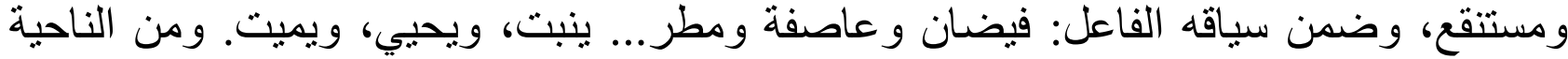

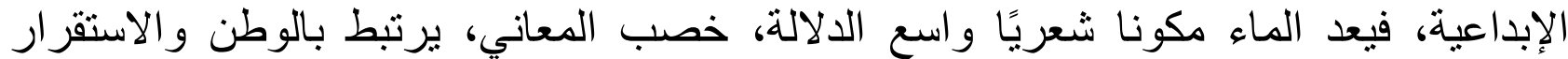

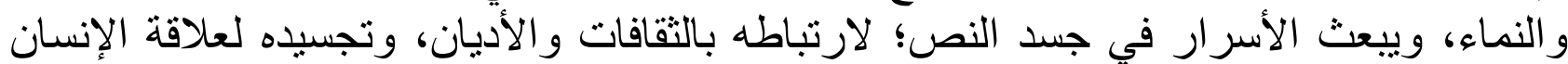
بيئتها، يزوده بما يحتاجه لحظة الفقدان بفاعلية بنائية عالية.

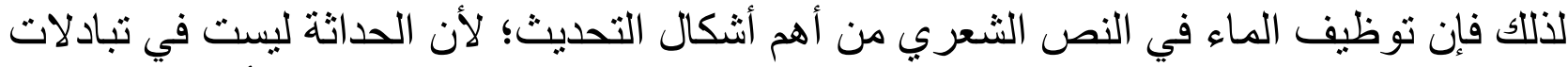

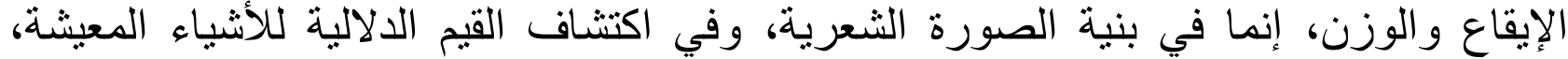

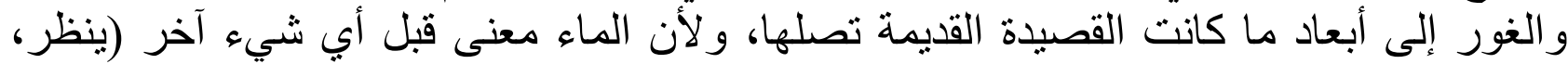
النصير، 2012)، فقد كثر الحديث عنه في الأشعار العُمانية ومن ذلان نذاء الفكر:

قول الثاعر عبد الله الخليلي في مطلع قصيدته الغزلية:

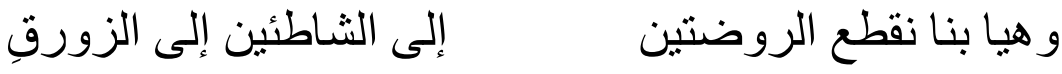

فنري ميله لاستخدام عناصر المياه المختلفة في لفظ (الثناطئين - الزورق إسى ).

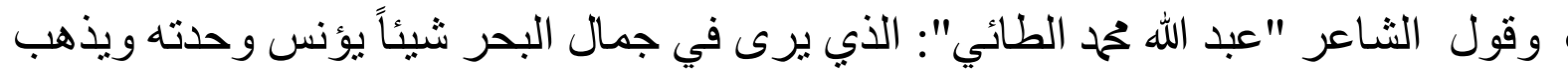

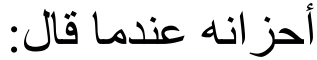

مرحبا بالبحر.. قد صاغ على الماء عقوده

و السما تمنحه الدر فيختار نضيده

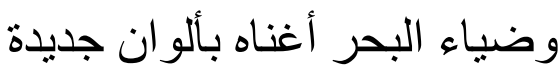

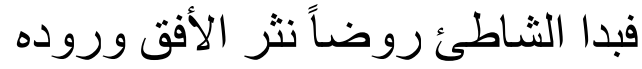

• كما يقول الثاعر عوض الليهي في شعريته "الماء تخون البرك":

لا نوقظي الروح

دعيها غارقة في ماء السديم

احرسيها من عشب طفولتكا فئاء 


$$
\text { فالبياض يعرف }
$$

مجر اه إن داهمه الطوفان

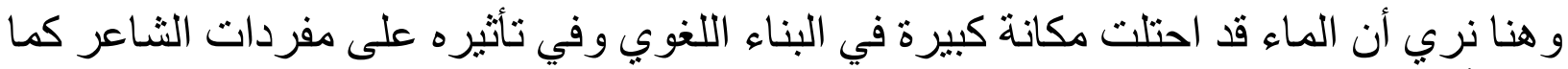

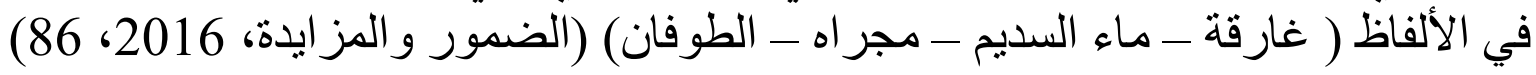

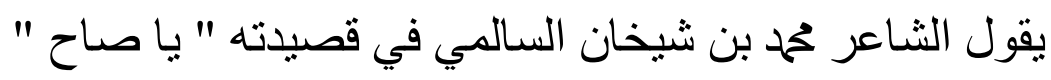

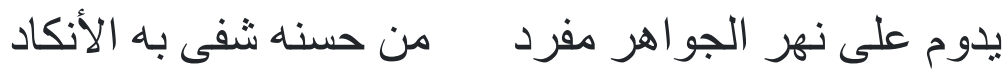

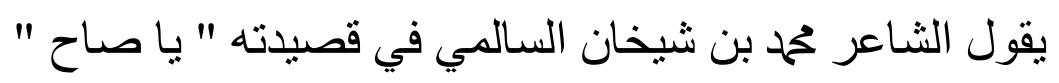

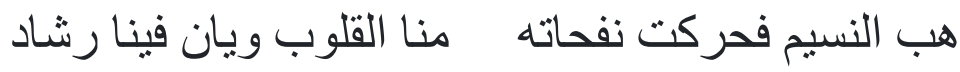

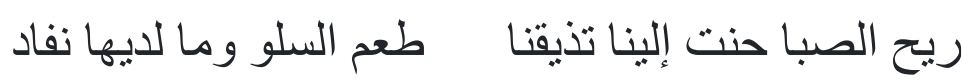

يقول الثاعر حمح بن شيخان السالمي في قصيدنه " يا صاح:

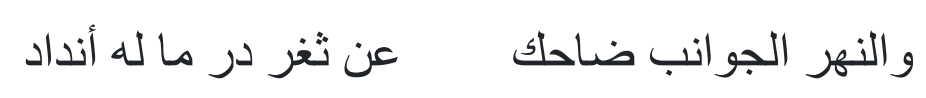

وعن الأمطار التي اكتسبت أهمية خاصة لاى العرب:

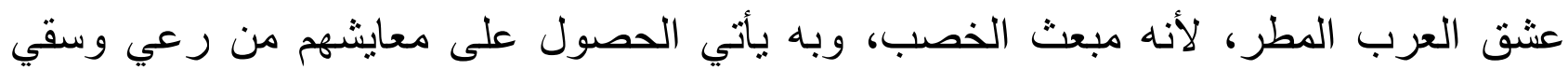

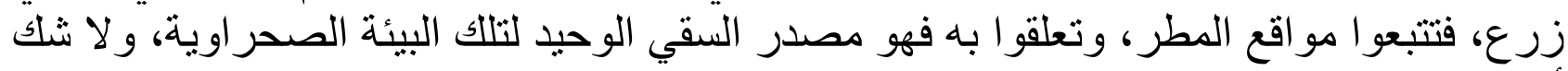

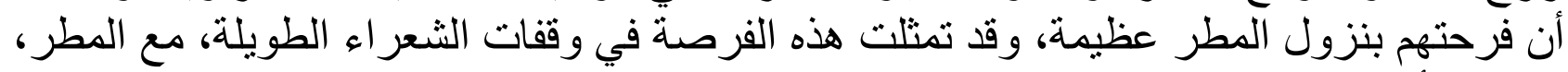

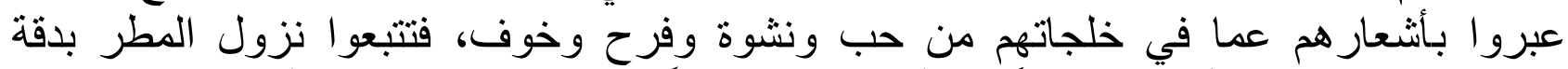
واهتمام كبيرين، منذ أن كان ودقاً إلي أن يصبح سيولاً تغطي الآكام و الوهاد (أبو علي، 2018:

$$
\text { فيقول سليمان الرحبي في قصيدته "سهرة": }
$$

في هذا المكان أمطرت سحب في كثيرة

يعرفها القرويون

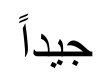

وقدم الهستيريا قادت شعاب الذاكرة

في غلواء الليل.

3. الصحراء:

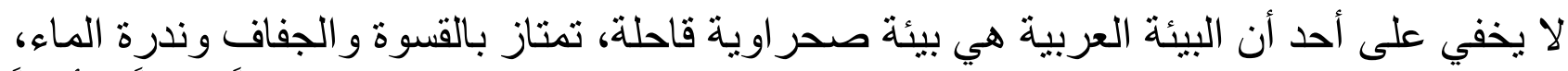

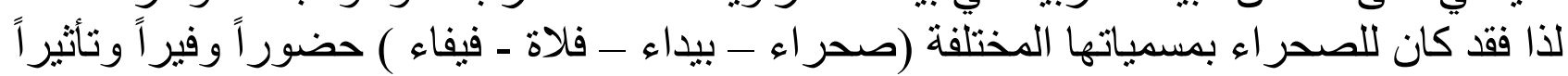

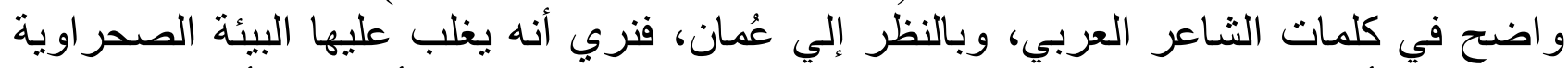

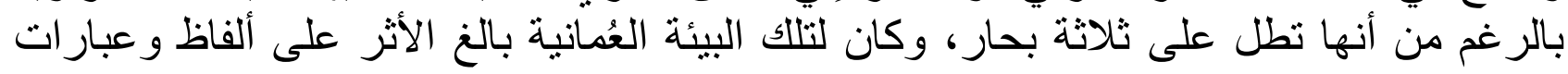

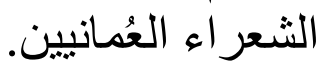
ويمكن تعريف الصحراء بأنها: الأرض المستوية اللينة، وهو اسم يحمل في معناه الاتساع 


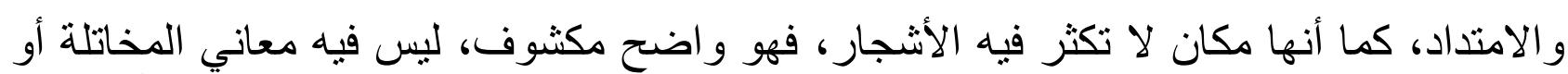

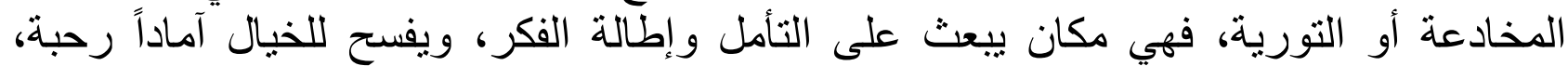

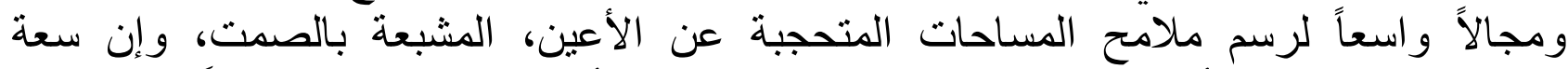

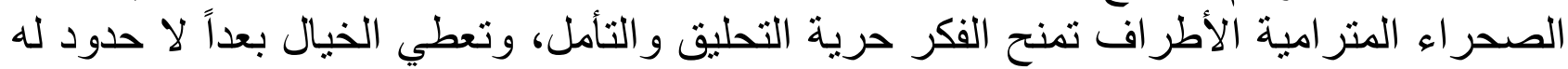

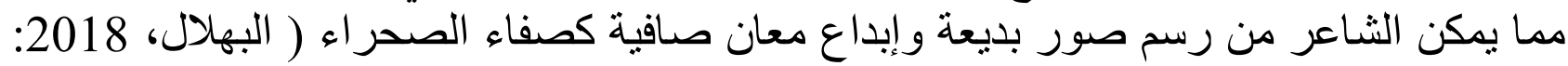

. (102

ومن أمثلة ورود الصحر اء في الثعر العُماني يقول الثشاعر" صالح الفهدي" واصفاً جموح الخيل في قصيدته :تميل النفس إلي الهوري":

ما إِنْ تَفْزَّ إلِى الْفَلاةِ طليقةً

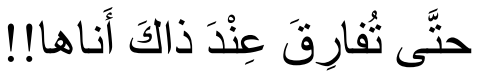

ويقول "هلال بن سعيد" في مدح نفسه في قصيدة اسمها " أهل خبر فيه النجيد لنا يروى":

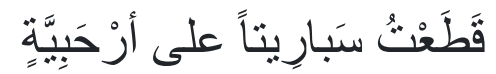

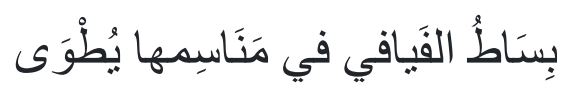

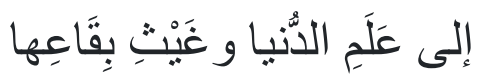

سعيد الذي من كَفِّهِ عُرِفَ الجَدْوَى

4. - الوديان

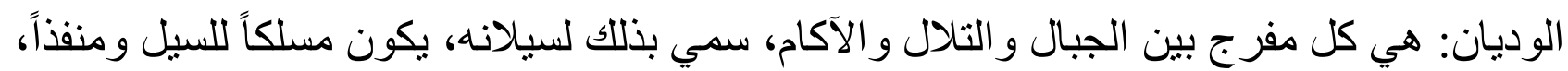

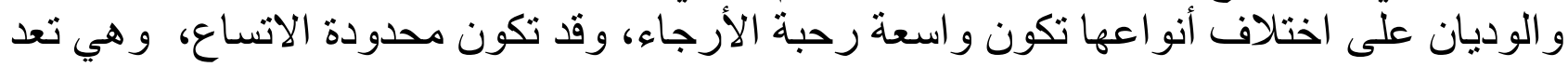
من مصادر إلهام الثعر اء. ومن أمثلة ورودها في الثُعر العُماني:

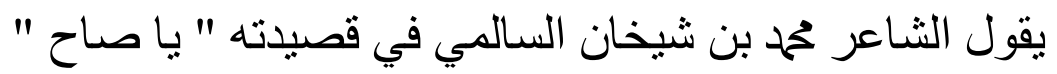

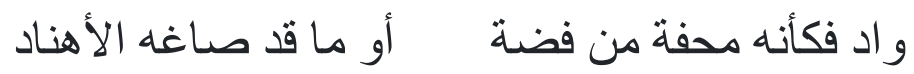

ويقول نفس الثاعر في قصيدته " بكل الأودية مغرم":

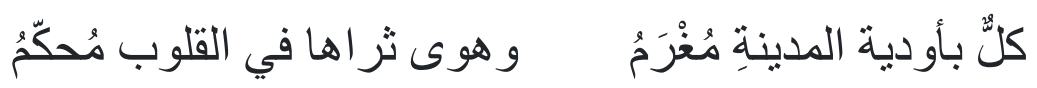

يقول الثناعر " هلال بن سعيد العُماني":

قلبي تذكَّرَ جيرةًَ في ساخِفٍ

وطويلِع مع قاعِة الوَعْسَاِِ

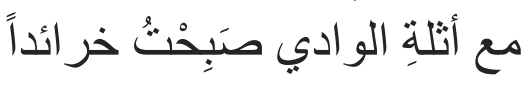

عنقاء مع غرثاء مع غيداء 


$$
\text { ويقول الطائي معبر اً عن بعد حبييته : }
$$

مالي أنا صب يعيش بو ادي وحبيبه : بيبه عن يعيش بوادي

ثانياً: ألفاظ الطبيعة السماوية:

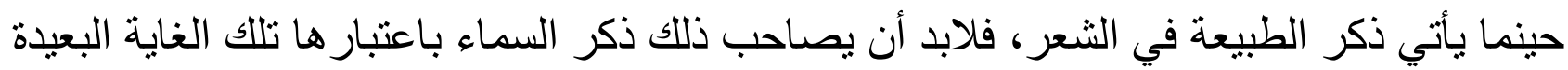

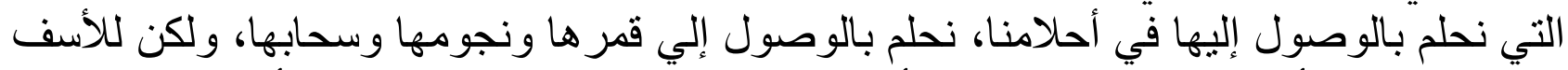

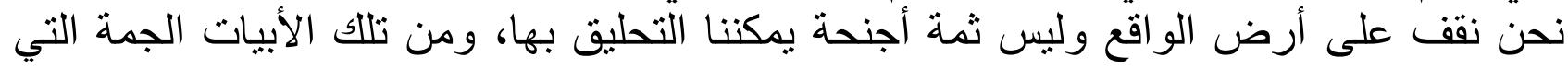
تتاولت الثعر السماء في الثعر العُماني نذكر لكم الآتي:

$$
\text { قول الطائي في قصيدته "رسالة إلي اللؤلؤة السائلة عن الخليج العربي": }
$$

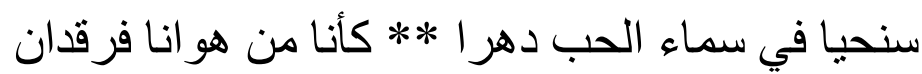

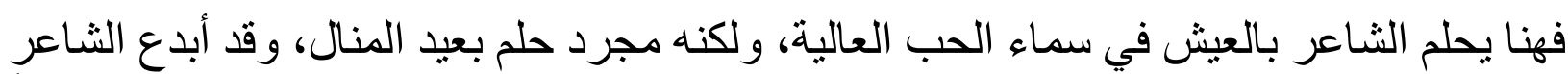

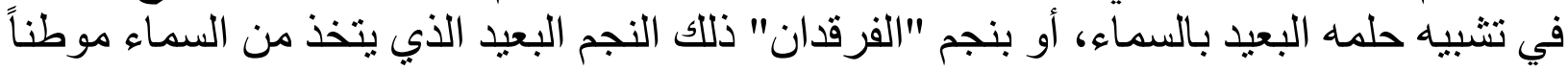

$$
\begin{aligned}
& \text { ويقول الثاعر "هلال بن سعيد العُماني" في قصيدته " لقد هجرتني أم سعيد وحبها": }
\end{aligned}
$$

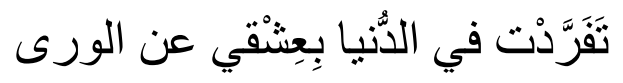

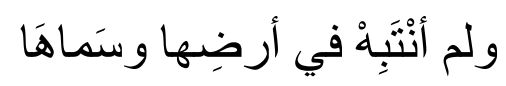

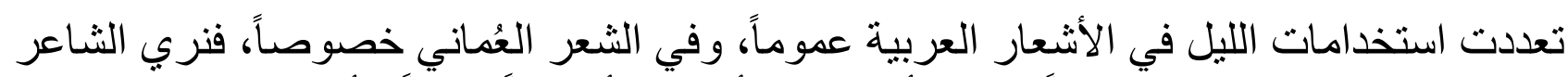

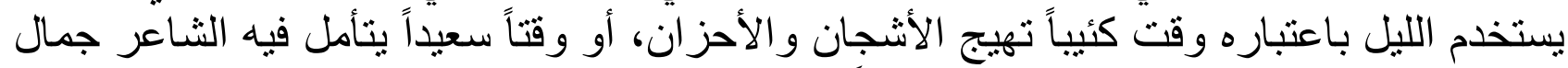

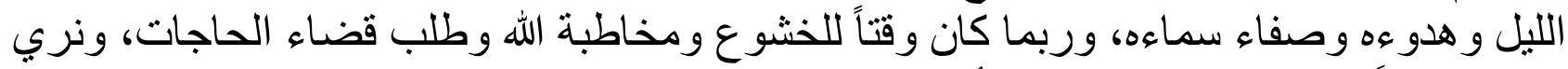
ذللك و اضحاً في الثعر العُماني في الأمثلة التالية:

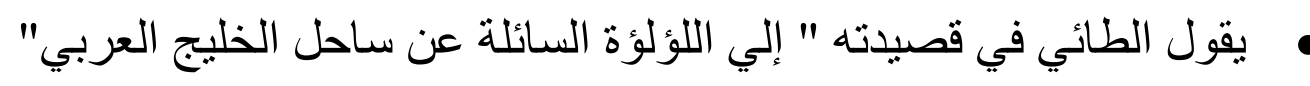
مرحبا بالبحر قد صاغ على الماء عقوده

و السما تمنحه الدر فيختار نضيده

و ضياء البدر أغناه بألوان جديدة

ويقول الثاعر سيف الرحبي في قصيدته " مدينة تستيقظ": تستيقظ آخر الليل،

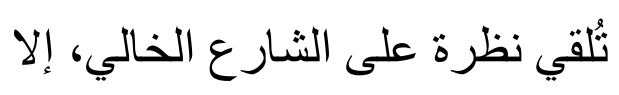

من أنفاس متقطعة، تعبره

بين الحين والآخر.

يقول الثـاعر الدكتور "صالح الفهدي" في قصيدته "رجو ال في الله": 


$$
\begin{aligned}
& \text { دعوتَّ في هجعاتِ الليلِ محتسِبًا }
\end{aligned}
$$

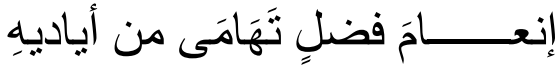

$$
\begin{aligned}
& \text { ويقول الثاعر أحمد الحارثي: } \\
& \text { ويارُبَّ ليلٍِ مُدجنِ الغَيَمِ قاتِِ }
\end{aligned}
$$

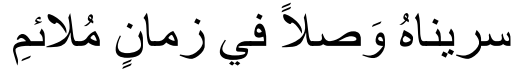

$$
\begin{aligned}
& \text { وَناز عَني فيه الرحيقُ مُسَوَّرٌ }
\end{aligned}
$$

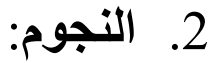

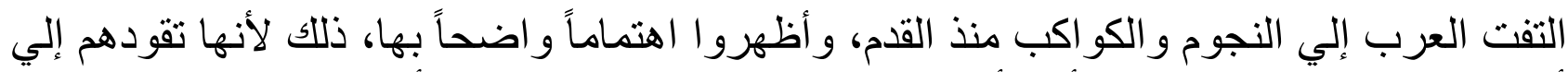

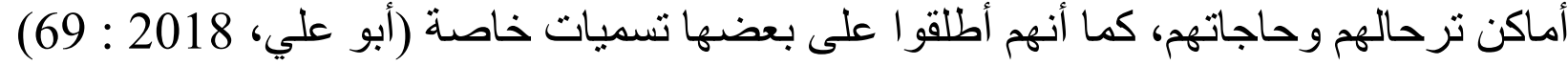

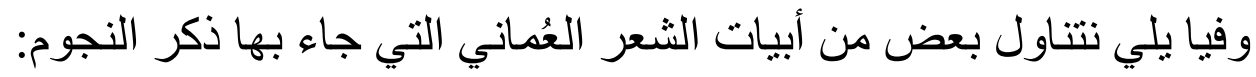

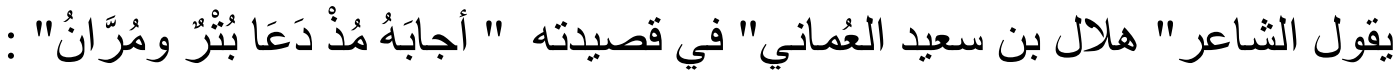

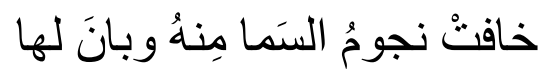
نَحْوَ المَغَارب إخْفَاءُ وطَيَرَانُ ويقول الثاعر أحمد الحاتي:

هذا سَميرُ دُجى الصبابِِ و الَجَوَى و النجُ ستَارِ في ذُرَى الأفلالكِ

يقول الطائي في قصيدنه " إلي اللؤلؤة السائلة عن ساحل الخليج العربي"

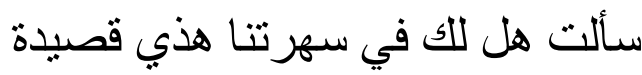

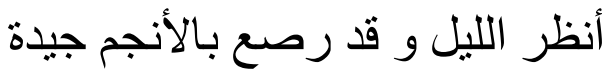
و أرمق الجو و قد لحن بالصمت نشيدة أفما حرك في القلب أحاسيس جديدة ؟

ويقول أيضاً في ديو انه الفجر الزاحف معبر اً عن حال الأمة العُمانية: وقد طال ليل الهوان المرير وفجر الكرامة لم يفلق

ويقول سيف الرحبي في قصيدته " مدينة تسنيقظ":

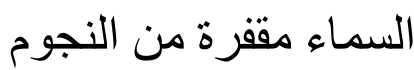

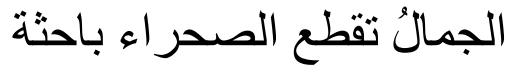
عن خيام العشيرة القطار اتُ تحلُم بالمسافرين.

ويقول الثناعر "هلال العُماني" في قصيدته " طيور المعالي في السماء حوثم": 


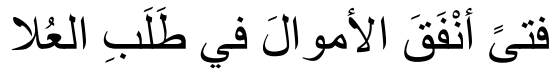

$$
\begin{aligned}
& \text { بِِشْرِ ولو أنَّ النجومَ دَرَالهِمُ }
\end{aligned}
$$

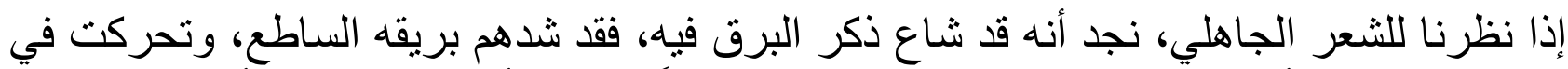

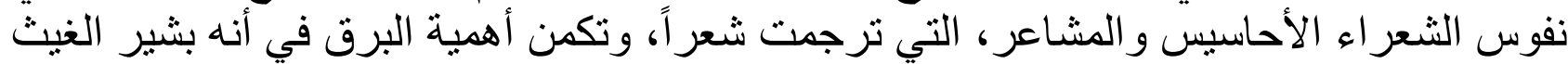

$$
\text { وسقوط المطر (أبو علي، } 2018 \text { : 70). }
$$

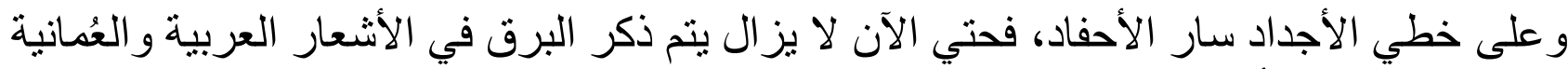
- و إن كان بدرجة أقل - ومن ذلك: الأن

يقول الثـاعر العُماني " هلال بن سعيد العُماني " في قصيدته "برق تبدي خفية بسناء": بَرْقُقُ تَبَدَّى خِفِية بسَنَّاء

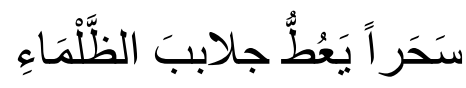

ويقول نفس الثناعر في قصيدته " طيور المعالي في السماء حوثم":

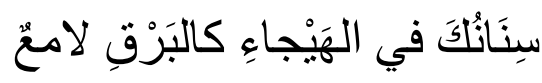

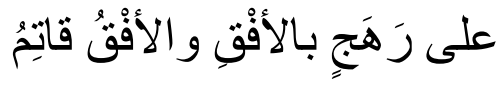

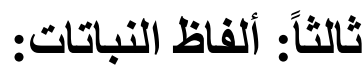

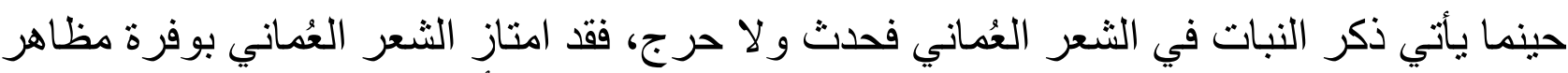

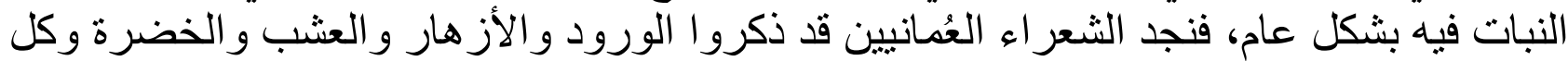
ما يتعلق بالحياة النباتية ومن أمثلة ذللك:

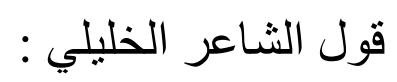

$$
\begin{aligned}
& \text { و هزي كياني و لا تشفقي } \\
& \text { قفيني على زهرة الزنبق } \\
& \text { ليدري السعيد به و الثثقي وهي لئي }
\end{aligned}
$$

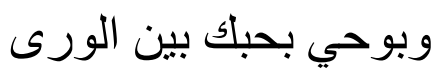

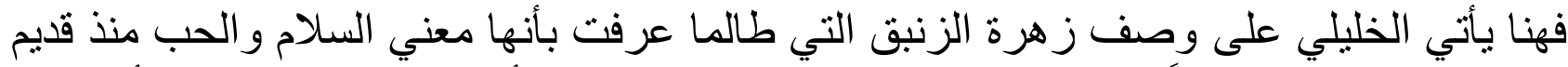

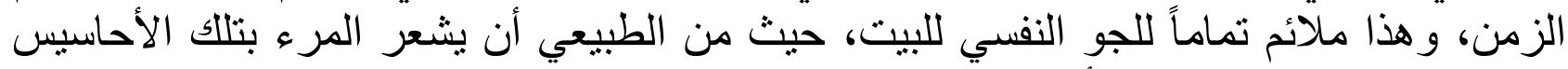
الر ائعة وبذلك ولت الصفاء عندما يأتي ذكر حبييته.

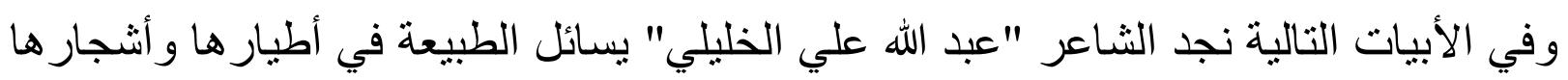

$$
\begin{aligned}
& \text { ما للأغصسان تأودها }
\end{aligned}
$$

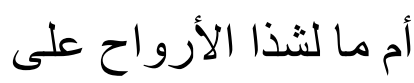

$$
\begin{aligned}
& \text { أم ما للورق بأغصنها } \\
& \text { فترى الأغصان بدوحتها لورى باعها }
\end{aligned}
$$




$$
\begin{aligned}
& \text { و الطير تهيم فيعدمها } \\
& \text { أتر اها ذكرت ماضيها } \\
& \text { نسمات الثعب وتسندها } \\
& \text { هذي الأرواح بأوردها } \\
& \text { يشجي الولهان مغردها }
\end{aligned}
$$

فنري في الأبيات السابقة وفرة من ألفاظ الطبيعة النباتية كما في الألفاظ ( الأغصان - الورق مهان

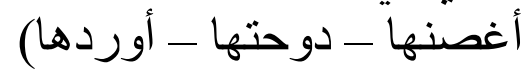
ويقول الطائي:

$$
\text { كأن عهوده أنسام خير ** يضم عبير ها أرج الجنان }
$$

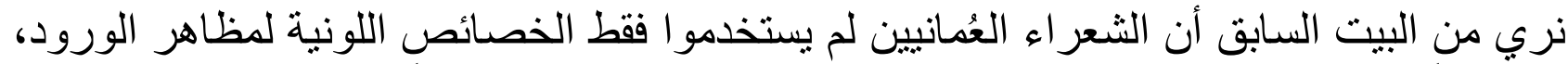

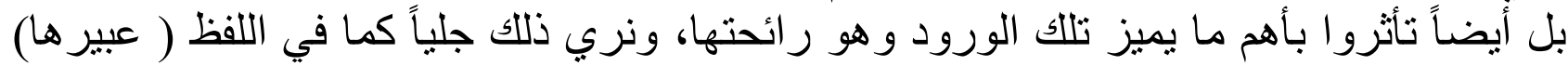

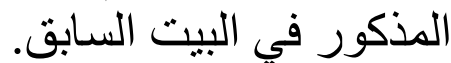

ونذكر صورة أخرى للنشاعر "هلال سالم السيابي" حيث يبدي لنا الثـاعر من خلالها إعجابه

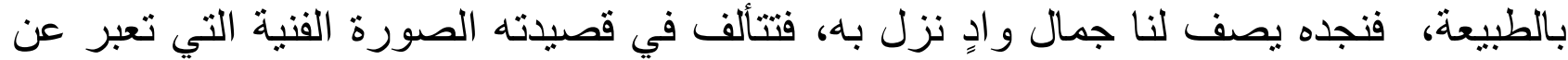

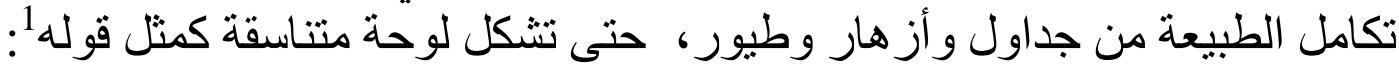

$$
\begin{aligned}
& \text { لبست حلة الربيع بروداً } \\
& \text { نفحت بالعبير من ريحانه } \\
& \text { بين زهر النسرين يبسم للورد بهن } \\
& \text { وينصب في هوى أقحوانه }
\end{aligned}
$$

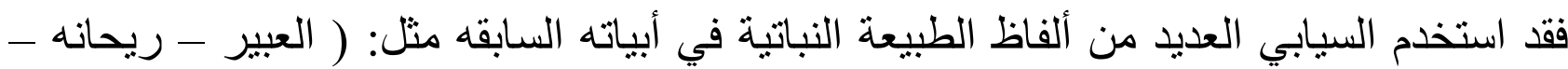

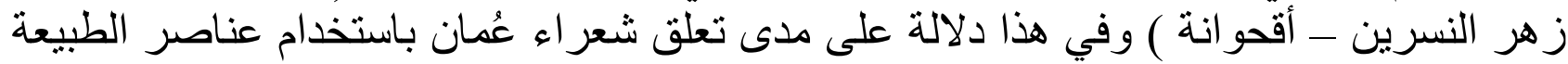
النباتية في ألفاظهم.

\section{المبحث الثاني: القيم الأسلوبية لألفاظ الطبيعة الحية (المتحركة)}

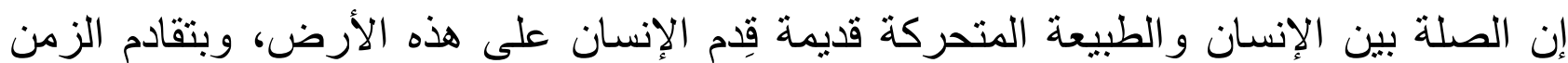

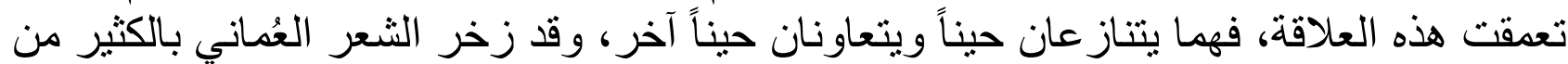

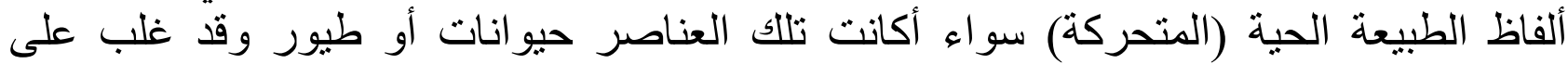

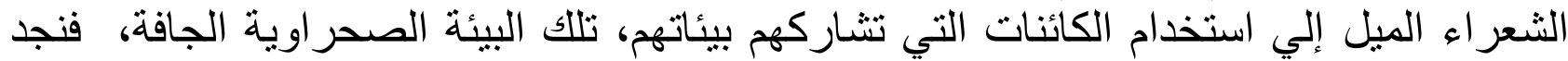
مثنا كثرة ذكر الخيل و الأغنام و السباع و العقبان ... إلخ. ويأتي ذلك واضحاً من أبيات الثاعر "هلال بن سعيد العُماني " في قصيدته "أجابه مذ دعا بتر 


$$
\begin{aligned}
& \text { أذاقَهم ضَرْبُ أسيافٍ يَدِبُُّ على }
\end{aligned}
$$

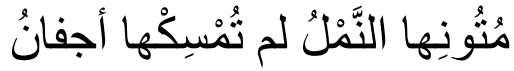

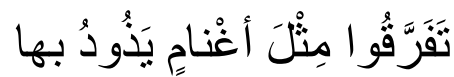

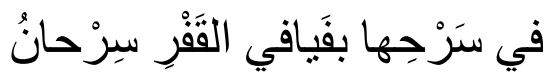

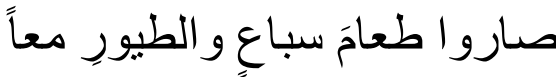

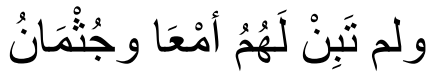

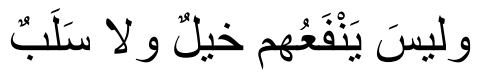

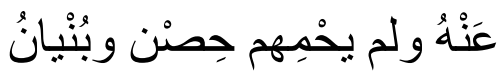

نجد في الأبيات السابقة وفرة من ألفاظ الطبيعة المتحركة مثل ( النمل ـ أغنام ـ سباع - الطيور -

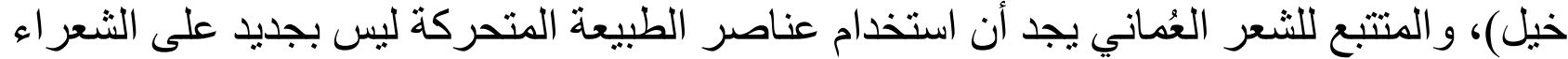
العُمانيين، وفيما يلي سنتناول عناصر الطبيعة الحية بشيء من التفصيل.

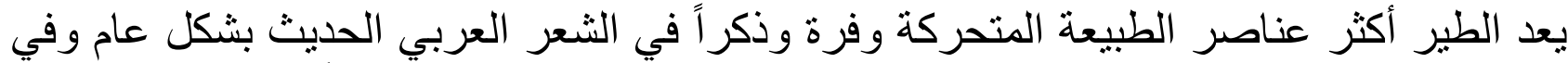

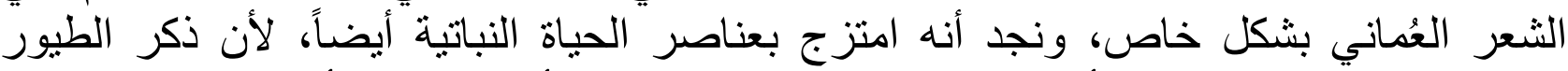

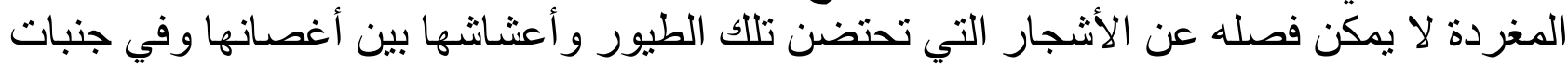

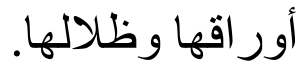

ويبدو ذلك جلياً في أبيات سالفة الذكر للخليلي والتي استخدمناها للالالة على ذكر الحياة

$$
\begin{aligned}
& \text { والطير تهيم فيعدمها } \\
& \text { أتر اها ذكرت ماضيها } \\
& \text { نسمات الثعب وتسندها } \\
& \text { هذي الأرواح بأوردها } \\
& \text { يشجي الولهان مغردها }
\end{aligned}
$$

نجد في الأبيات السابقة بعضاً من الألفاظ التي تبين تعلق الثاعر بالحياة الطبيعية وبالأخص الطير

$$
\text { و هذه الألفاظ هي: ( الطير - مغردها ) . }
$$

ويقول الثاعر تحمد بن شيخان السالمي في قصيدته " كل الأودية":

تشتدو البلابلُ سَحرةًَ فيَهيجُهَا

ويقول الثاعر "هلال بن سعيد العُماني" في قصيدته " برق تبدي خفية بسناء":

$$
\begin{aligned}
& \text { وحمَام أيلكٍ ردّدَ الكافاتِ في }
\end{aligned}
$$

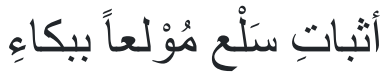


قد هاجَهُ دهرُ مضى بلذاذةٍ

ورغيد عيش قد مضنى بِهَنايٍِ

ويقول "العُماني" أيضاً في قصيدته " أجابه مذ دعا بتر ومران":

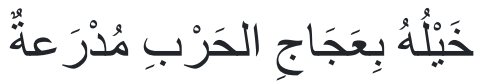

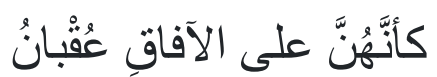

ويقول أيضاً في قصيدته " طيور المعالي في السماء حواثم":

طيورُ المَعَالي في السماءٍِ حَوائُُ

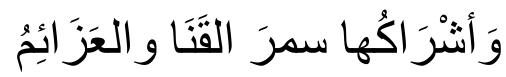

ويقول في قصيدته "طيور المعالي في السماء حوثث":

فتى سال بالأقطار من حدِّ سَيْفِهِ

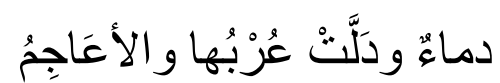

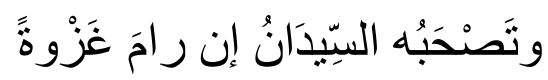

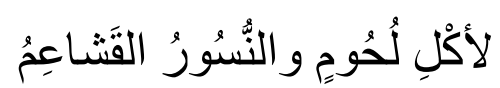

إذا ذكرت الخيل، ذكر العرب، فللعرب تاريخ طويل مع الخيل؛ فقديماً كان الجواد هو أهم عناصر

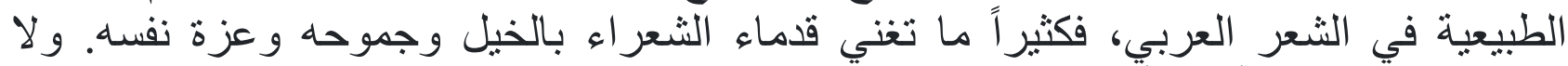

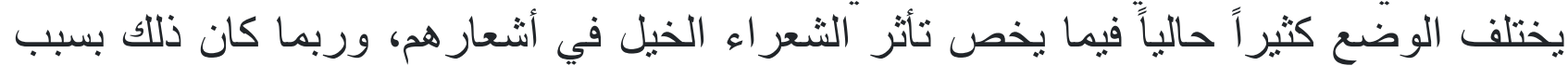

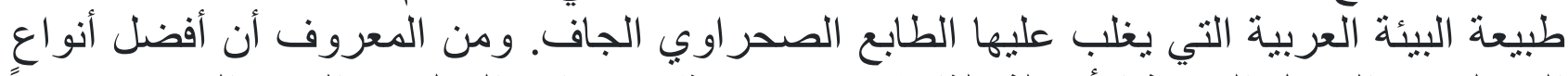

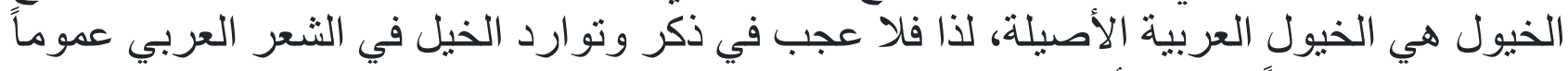
و العُماني خصوص هي الغياً، ومن الأمثلة على ذلألك في الثعر العُماني:

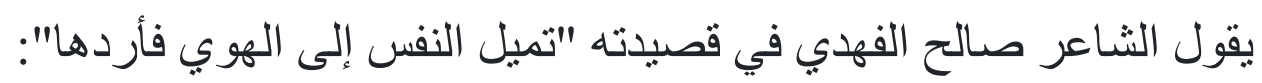
نفسي تميلُ إِلى الْهَوى فَأَرُدُّها

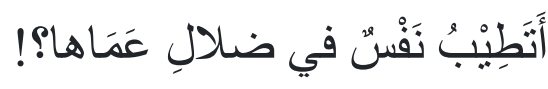

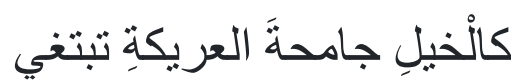

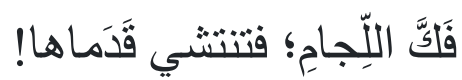

ويقول "هلال بن سعيد العُماني" في قصيدته " طيور المعالي في السماء حواثم":

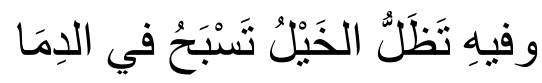

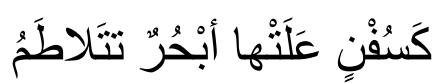




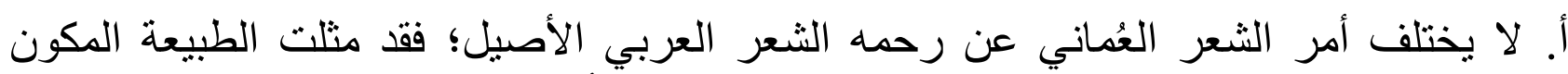

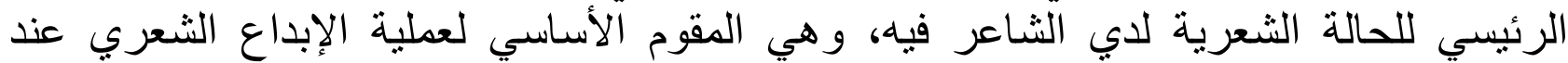

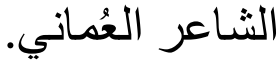

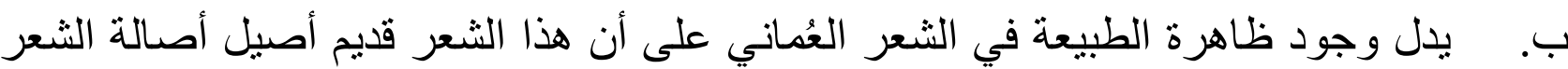

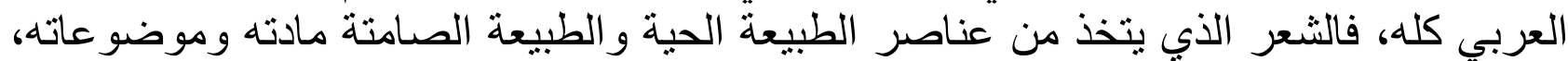
يكون صادق العاطفة قوي المعنى و الدلالة.

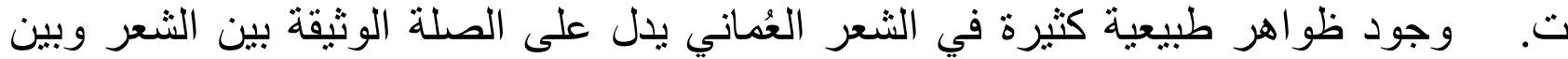
بيئته التي نشأ وتربي وترعع فيها، فهو لم ينسلخ عنها ولم يفتن بغير ها، ولئ وإنما يعتز بها ويفخر

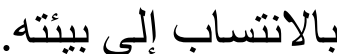

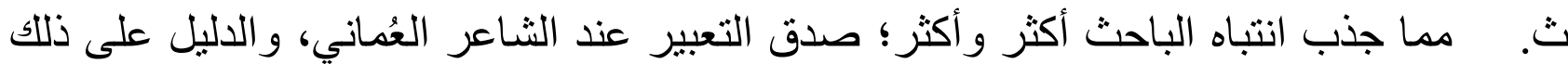

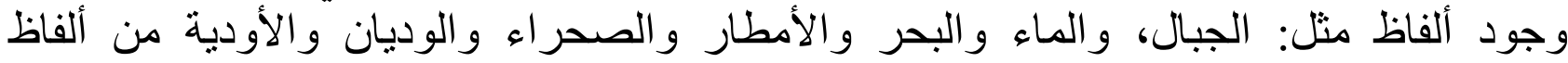

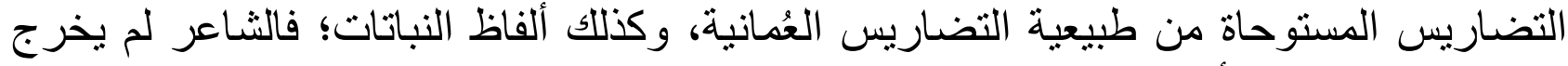
عن عباءته العربية الأصيلة.

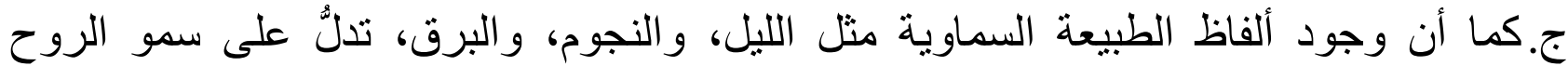

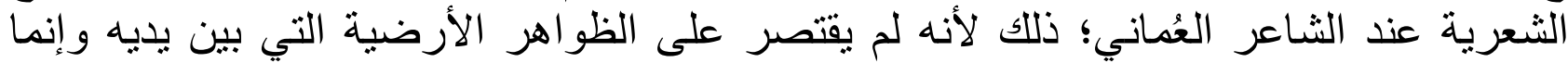
تسمو روحه إلى آفاق فسيحة ورحبة من الكون المحيط. ح.ذكر الخيل و الأغنام والسباع و العقبان وغير ها، يصور تبادية الكاتلات الإيقاع و الوزن في بنية الصورة

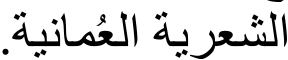

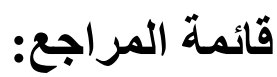
أبو شعبرة، باسر ذيب طاهر. (2018) ـ المعجم الثعرى ومصادره في شعر عبدالمنعم الرفاعي:

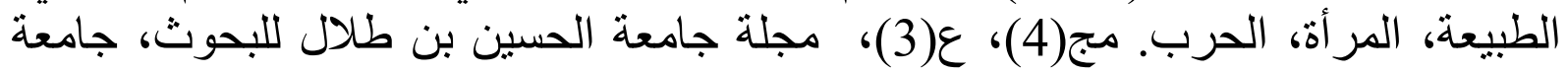

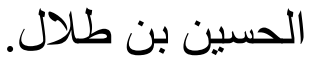

أبوعلي، خالد نبيل. (2018). ألفاظ الطبيعة في جمهرة أثنعار العرب: دراسة أسلوبية. مج22، العالة 2ع، مجلة جامعة الأقصى - سلسلة العلوم الانسانية. البهلال، خالد بن فهد. (2018). المتنز هات في الثعر العباسي، ع 112، جامعة القاهرة، كلية دار

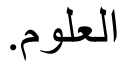
الزبير، علي عبده أحمد صالح. (2010). تجليات الطبيعة في شعر الهمدانى. ع(23)، جامعة عدن

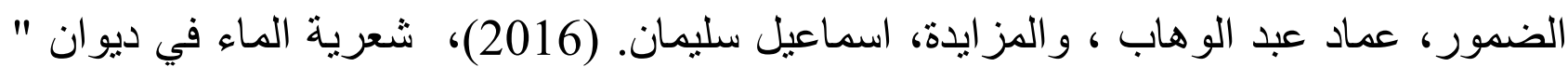

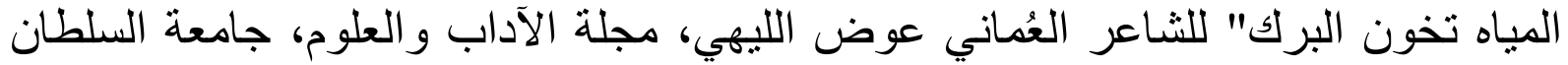

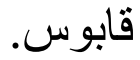
خلف، سلام أحمد. (2012). الأثر النفسي للطبيعة في شعر أبن الرومي، مج 18، ع 74، مجلة 


$$
\text { كلية التربية الاساسية كلية الآداب جامعة بغداد(54-84). }
$$

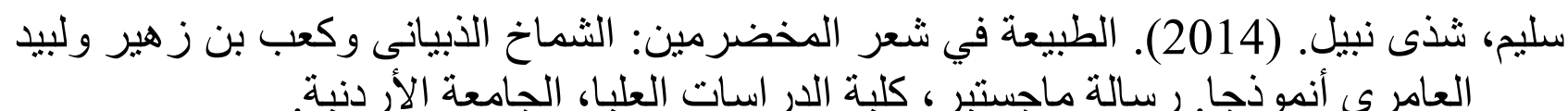

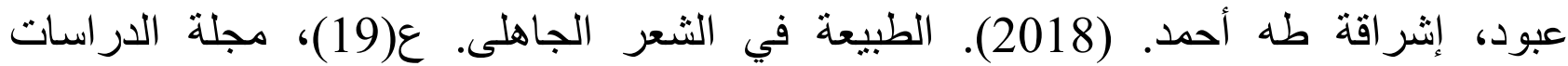

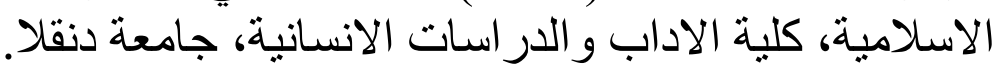

كنعان، أحمد تحمد. (2002)، الطبيعة المفهوم و المخالفة، ع (12)، العيئة العالمية للإعجاز العلمي في القرآن و السنة.

\section{ARABIC REFERENCES IN ROMAN ALPHABET}

'Abu Shaeirat, Yasir Dhyb Tahir. (2018). Almejam Alshueraa Wamasadiruh Fi Shaear Ebdalmnem Alrfaey: Altbyet, Almar'ata, Alharb. Mj(4), E(3), Majalat Jamieat Alhusayn Bin Talal Lilbihwth, Jamieat Alhusayn Bin Talal.

'Abuealay, Khalid Nbil. (2018). 'Alfaz Altabieat Fi Jamhirat 'Ashear Alerb: Dirasat 'Asliwbiat. Mj22, E2, Majalat Jamieat Al'aqsaa - Silsilat Aleulum Alainsaniat.

Albihlal, Khalid Bin Fahd. (2018). Almutanazihat Fi Alshier Aleabasii, E 112, Jamieat Alqahirati, Kuliyat Dar Aleulum.

Alzubir, Eali Eabdah 'Ahmad Salih. (2010). Tajaliyat Altabieat Fi Shaear Alhmdana. E(23), Jamieat Eadn .

aldumuar, eimad eabd alwahhab , walmizayidat, 'iismaeil salayman. (2016), shaeriat alma' fi diwan " almiah takhawn alburka" lilshshaeir aleumany eiwad alliyhi, majalat aladab waleulumi, jamieat alsultan qabus.

khulfa, salam 'ahmud. (2012). al'athar alnafsiu liltabieat fi shaear 'abn alruwmii, maj 18, e 74, majalat kuliyat altarbiat al'asasiat kuliyat aladab jamieat baghdad(57-84).

salim, shadhaa nubil. (2014). altabieat fi shaear almukhadrimina: alshimakh aldhabianaa wakaeb bin zahir walibayd aleamirii 'unmudhija. risalat majstir, kuliyat aldirasat aleulya, aljamieat al'urduniyat.

eibud, 'iishraqat th 'ahmud. (2018). altabieat fi alshier aljahlaa. ea(19), majalat aldirasat alaslamyt, kuliyat aladab waldirasat alainsaniata, jamieatan dinaqala.

kunean, 'ahmad mahmud. (2002), altabieat almafhum walmukhalifat, e (12), alhayyat alealamiat lil'iiejaz aleilmii fi alquran walsanat. 